\title{
Influence of $\mathrm{Nb}$ Addition on Magnetic Properties of the Nanocrystalline $\left(\mathrm{Nd}_{10} \mathrm{Fe}_{67} \mathrm{~B}_{23}\right)_{100-x} \mathrm{Nb}_{x}$ (where $\left.x=1,2,4\right)$ Alloy Ribbons
}

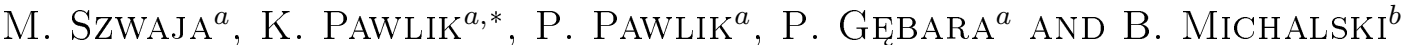 \\ ${ }^{a}$ Institute of Physics, Częstochowa University of Technology, al. Armii Krajowej 19, 42-200 Częstochowa, Poland \\ ${ }^{b}$ Faculty of Materials Engineering, Warsaw University of Technology, Wołoska 141, 02-507 Warsaw, Poland \\ In the present work the magnetic properties and phase constitution of $\left(\mathrm{Nd}_{10} \mathrm{Fe}_{67} \mathrm{~B}_{23}\right)_{100-x} \mathrm{Nb}_{x}$ (where $x=1$, \\ $2,4)$ alloys in the form of ribbons were investigated. The base alloys were prepared by arc-melting the high \\ purity elements with pre-alloyed Fe-B under an Ar atmosphere. The ribbon samples were obtained by controlled \\ atmosphere melt-spinning technique. In order to generate the nanocrystalline microstructure and hard magnetic \\ properties, samples were annealed at various temperatures (from $923 \mathrm{~K}$ to $1023 \mathrm{~K}$ ) for $5 \mathrm{~min}$. The aim of the \\ present work was to determine the influence of $\mathrm{Nb}$ admixture and annealing conditions on the phase constitution \\ and magnetic properties.
}

DOI: 10.12693 /APhysPolA.127.623

PACS: 75.20.En, 75.75.-c, 75.75.Cd

\section{Introduction}

The Nd-Fe-B permanent magnets are widely used in the latest technologies and their importance is still growing for they exhibit excellent magnetic properties [1-3]. The appropriate structure and phase constitution of these materials have a significant impact on the value of coercitivity ${ }_{J} H_{\mathrm{c}}$, remanence $B_{\mathrm{r}}$ and maximum energy product $(B H)_{\max }$. In recent years, one of the most commonly used methods of processing such magnets is the melt spinning rapid solidification technique. Appropriate composition and annealing conditions are crucial for obtaining the best magnetic properties [4]. Interesting results for magnets produced from base $\mathrm{RE}-\mathrm{Fe}-\mathrm{B}$ alloys doped with $\mathrm{Nb}$ are presented in [5-8]. The $\mathrm{Nb}$ addition has not only a significant influence on the glass forming ability, but also reduces the growth of nanocrystalline grains formed during heat treatment [8]. The annealing process is also an important factor in formation of the microstructure and tailoring of magnetic properties. Therefore, it is crucial to determine the effect of $\mathrm{Nb}$ admixture and heat treatment conditions on the phase constitution and magnetic properties of $\left(\mathrm{Nd}_{10} \mathrm{Fe}_{67} \mathrm{~B}_{23}\right)_{100-x} \mathrm{Nb}_{x}$ (where $x=1,2,4$ ) alloys in a form of ribbons.

\section{Samples preparation and experimental method}

Base alloys with nominal compositions of $\left(\mathrm{Nd}_{10} \mathrm{Fe}_{67} \mathrm{~B}_{23}\right)_{100-x} \mathrm{Nb}_{x}$ (where $x=1,2,4$ ) were produced from the high purity elements and pre-alloyed Fe-B alloy of known composition by arc-melting under an Ar atmosphere. Samples were re-melted several

\footnotetext{
* corresponding author; e-mail: kpawlik@wip.pcz.pl
}

times in order to get better homogeneity. Subsequently, ribbons were produced by the melt-spinning technique under the Ar atmosphere at linear velocity of the copper roll surface of $35 \mathrm{~m} / \mathrm{s}$. The samples were annealed at various temperatures from $923 \mathrm{~K}$ to $1023 \mathrm{~K}$ for $5 \mathrm{~min}$ under protective argon atmosphere.

The phase analysis was carried out using X-ray diffractometry (XRD) with $\mathrm{Cu} K_{\alpha}$ radiation. Thermal parameters of alloys were determined using differential scanning calorimetry (DSC) and differential thermal analysis (DTA). Both the DSC and DTA measurements were carried out at a constant heating rate of $10 \mathrm{~K} / \mathrm{min}$. Room temperature hysteresis loops were measured by LakeShore 7307 vibrating sample magnetometer at external magnetic field up to $2 \mathrm{~T}$.

\section{Results and discussion}

The X-ray diffraction for $\left(\mathrm{Nd}_{10} \mathrm{Fe}_{67} \mathrm{~B}_{23}\right)_{100-x} \mathrm{Nb}_{x}$ (where $x=1,2,4$ ) alloy ribbon samples in the as-cast state revealed their amorphous structure, as shown by the lack of peaks corresponding to crystalline phases. Annealing at $923 \mathrm{~K}$ and $943 \mathrm{~K}$ for $5 \mathrm{~min}$ resulted in some changes in the crystal structure of the material. Broadened peaks corresponding to the crystalline phases are shown in the XRD scans. Small intensity of these peaks in comparison with the level of background does not allow clear identification of crystalline phases present in the samples.

The XRD patterns measured for $\left(\mathrm{Nd}_{10} \mathrm{Fe}_{67} \mathrm{~B}_{23}\right)_{100-x} \mathrm{Nb}_{x}$ (where $x=1,2,4$ ) alloy ribbons annealed at $963 \mathrm{~K}$ for $5 \mathrm{~min}$, are shown in Fig. 1a. The short time annealing for $5 \mathrm{~min}$ at $963 \mathrm{~K}$ and at higher temperatures led to nucleation and growth of the crystalline phases. The $\mathrm{Nd}_{2} \mathrm{Fe}_{14} \mathrm{~B}$ hard magnetic phase is observed in all tested samples. For an alloy containing 1 at.\% of $\mathrm{Nb}$, short time annealing also led 


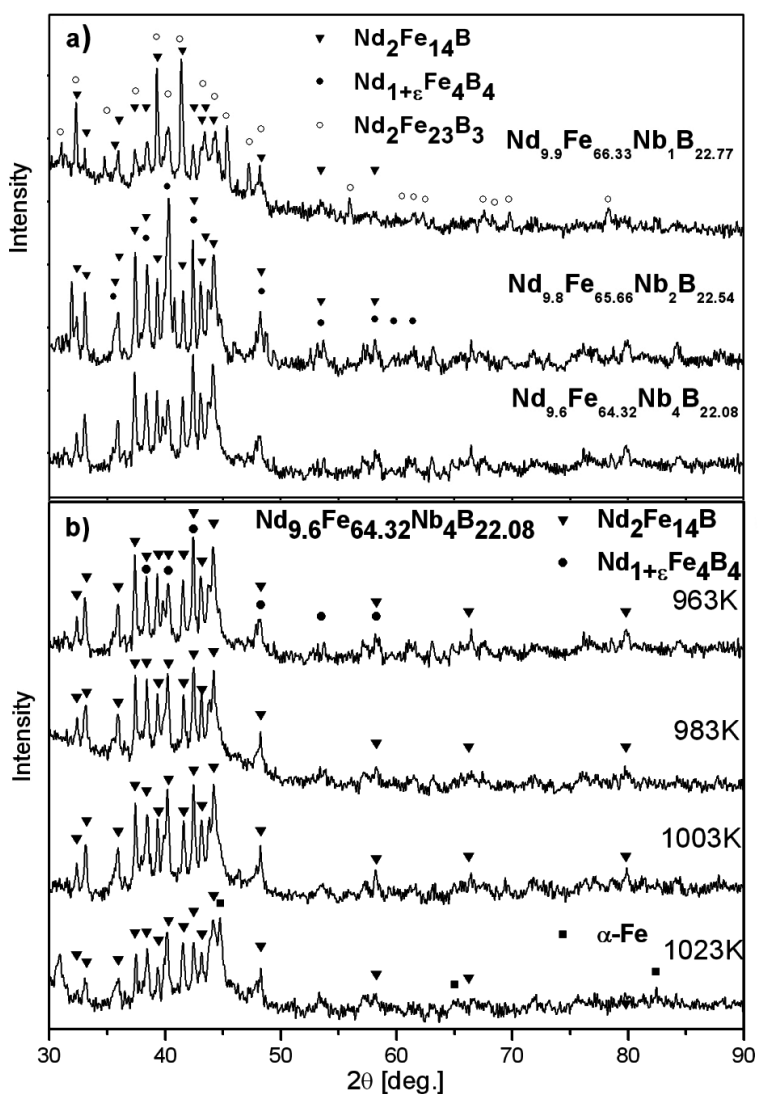

Fig. 1. X-ray diffraction patterns measured for $\left(\mathrm{Nd}_{10} \mathrm{Fe}_{67} \mathrm{~B}_{23}\right)_{100-x} \mathrm{Nb}_{x}$ (where $x=1,2,4$ ) alloy ribbon samples annealed at $963 \mathrm{~K}$ for $5 \mathrm{~min}$ (a) and for $\mathrm{Nd}_{9.6} \mathrm{Fe}_{64.32} \mathrm{Nb}_{4} \mathrm{~B}_{22.08}$ alloy ribbon samples annealed at $963-1023 \mathrm{~K}$ for $5 \mathrm{~min}(\mathrm{~b})$.

to formation of the $\mathrm{Nd}_{2} \mathrm{Fe}_{23} \mathrm{~B}_{3}$ metastable phase [9]. However, at higher contents of $\mathrm{Nb}(2,4$ at.\%) a presence of the $\mathrm{Nd}_{1+\varepsilon} \mathrm{Fe}_{4} \mathrm{~B}_{4}$ paramagnetic phase was revealed. The increase of annealing temperature does not change the phase constitutions of alloys (Fig. 1b). Furthermore, the intensity of the peaks corresponding to observed crystalline phases also does not significantly change. In case of $\mathrm{Nd}_{9.6} \mathrm{Fe}_{64.32} \mathrm{Nb}_{4} \mathrm{~B}_{22.08}$ alloy ribbon annealed at $1023 \mathrm{~K}$ the XRD peaks corresponding to the soft magnetic $\alpha$-Fe phase were also presented.

The DSC curves obtained for the $\left(\mathrm{Nd}_{10} \mathrm{Fe}_{67} \mathrm{~B}_{23}\right)_{100-x} \mathrm{Nb}_{x}$ (where $\left.x=1,2,4\right)$ alloy ribbon samples are shown in Fig. 2.

TABLE

The crystallization temperatures $T_{x 1}$ and $T_{x 2}$ and melting temperatures $T_{\mathrm{m}}$ determined for $\left(\mathrm{Nd}_{10} \mathrm{Fe}_{67} \mathrm{~B}_{23}\right)_{100-x} \mathrm{Nb}_{x}$ (where $\left.x=1,2,4\right)$ alloy ribbons in as-cast state.

\begin{tabular}{c|c|c|c}
\hline \hline$x$ & $T_{x 1}[\mathrm{~K}]$ & $T_{x 2}[\mathrm{~K}]$ & $T_{\mathrm{m}}[\mathrm{K}]$ \\
\hline 1 & 943 & 973 & 1427 \\
2 & 960 & 977 & 1381 \\
4 & 963 & 975 & 1379
\end{tabular}

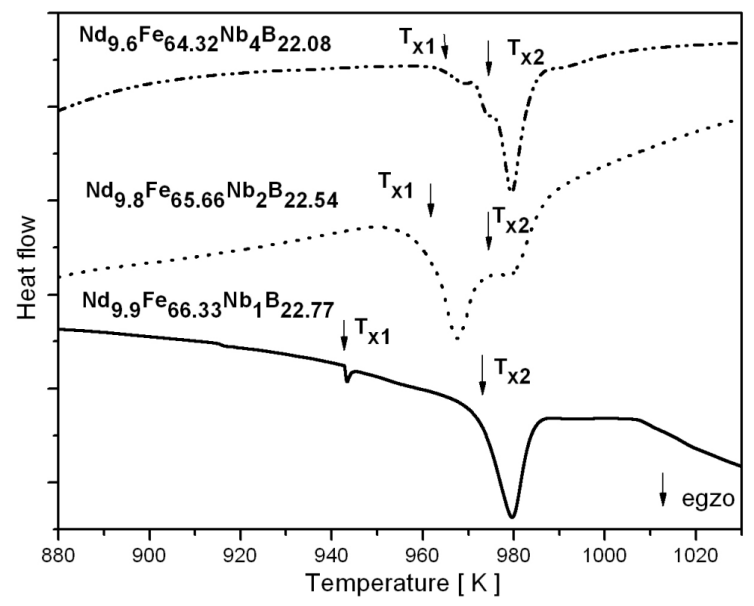

Fig. 2. DSC curves measured for the $\left(\mathrm{Nd}_{10} \mathrm{Fe}_{67} \mathrm{~B}_{23}\right)_{100-x} \mathrm{Nb}_{x}$ (where $\left.x=1,2,4\right)$ alloy ribbon samples after annealing.

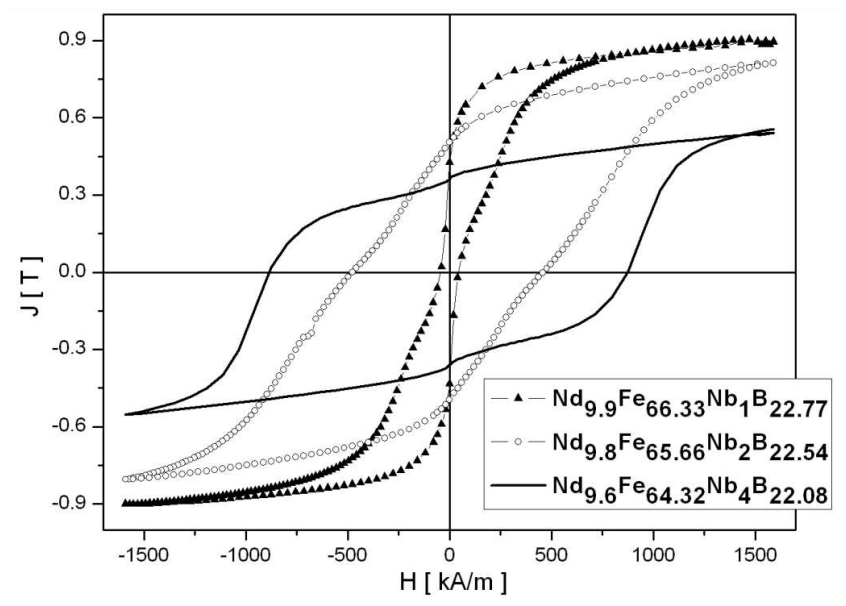

Fig. 3. The hysteresis loops measured for the $\left(\mathrm{Nd}_{10} \mathrm{Fe}_{67} \mathrm{~B}_{23}\right)_{100-x} \mathrm{Nb}_{x}$ (where $\left.x=1,2,4\right)$ alloy ribbon samples annealed at $963 \mathrm{~K}$ for $5 \mathrm{~min}$.

From the DSC and DTA curves, the crystallization temperature $\left(T_{x 1}, T_{x 2}\right)$ and melting temperature $\left(T_{\mathrm{m}}\right)$ were determined. The values of these parameters are shown in Table. A small peak of crystallization on the DSC curve measured for the $\mathrm{Nd}_{9.9} \mathrm{Fe}_{66.33} \mathrm{Nb}_{1} \mathrm{~B}_{22.77}$ alloy ribbon confirms a presence of the $\mathrm{Nd}_{2} \mathrm{Fe}_{23} \mathrm{~B}_{3}$ metastable phase [9] $\left(T_{x 1}=943 \mathrm{~K}\right)$, while a large peak corresponds to crystallization of the $\mathrm{Nd}_{2} \mathrm{Fe}_{14} \mathrm{~B}$ hard magnetic phase $\left(T_{x 2}=973 \mathrm{~K}\right)$. In case of 2 and 4 at. $\%$ of $\mathrm{Nb}$ containing alloys two-stage crystallizations confirm different phase constitution of these alloys. The hysteresis loops of ribbon after annealing at $963 \mathrm{~K}$ for $5 \mathrm{~min}$, are shown in Fig. 3.

The increase of $\mathrm{Nb}$ content in the alloy composition results in significant increase of the coercivity field ${ }_{J} H_{\mathrm{c}}$ from $44 \mathrm{kA} / \mathrm{m}$ for the alloy containing 1 at. $\%$ of $\mathrm{Nb}$ to $882 \mathrm{kA} / \mathrm{m}$ for the ribbon containing 4 at.\% of Nb. Furthermore, saturation magnetization decreases with increase of $\mathrm{Nb}$ contents. This is somehow related to the increase of the volume fraction of hard magnetic phase. 
The dependence of polarization remanence $J_{\mathrm{r}}$, the maximum magnetic energy product $(B H)_{\max }$ and coercivity ${ }_{J} H_{\mathrm{c}}$ on the annealing temperature for the investigated alloys are shown in Fig. 4.

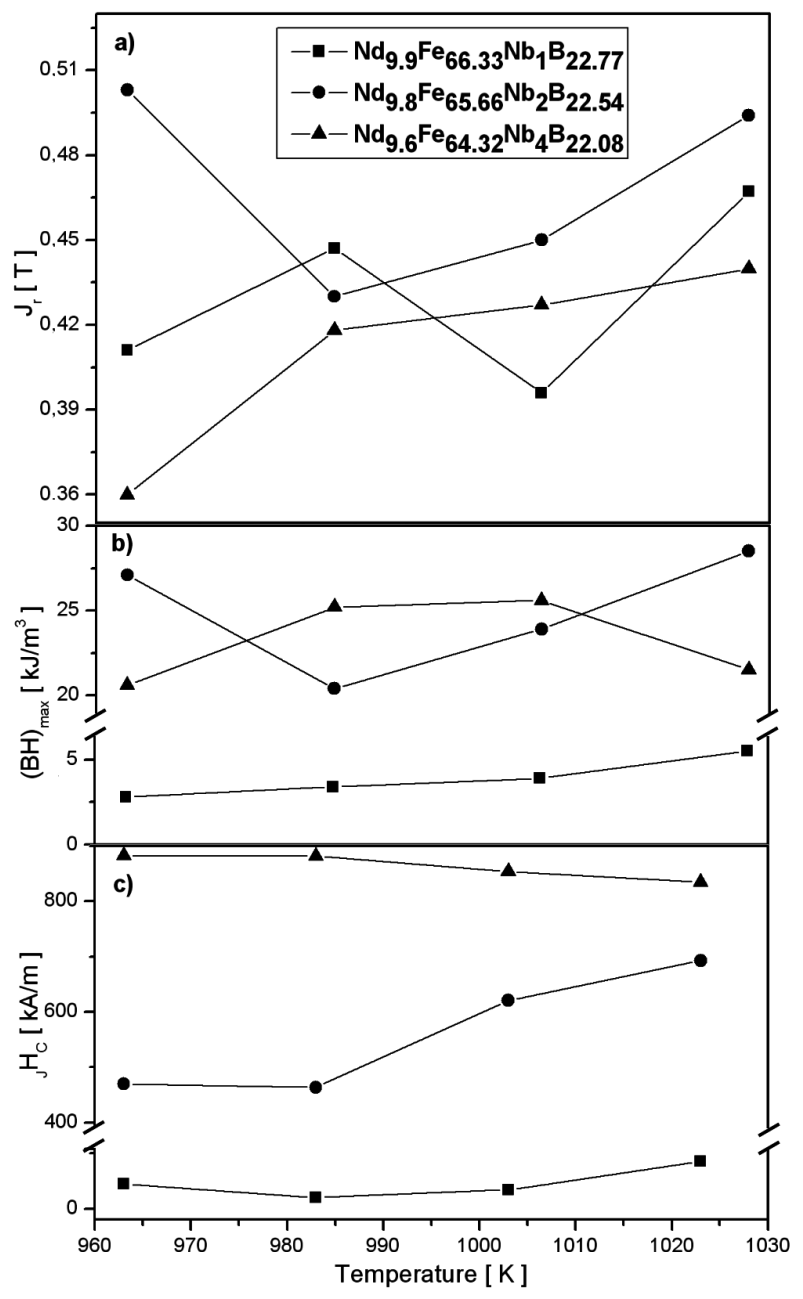

Fig. 4. The influence of $\mathrm{Nd}$ addition and annealing temperature on the remanence $J_{\mathrm{r}}(\mathrm{a})$, maximum energy product $(B H)_{\max }(\mathrm{b})$ and coercivity ${ }_{J} H_{\mathrm{c}}(\mathrm{c})$.

The samples of all alloys annealed at temperatures lower than $963 \mathrm{~K}$ reveal soft magnetic properties. For higher annealing temperatures (above $963 \mathrm{~K}$ ) hard magnetic properties are induced. It was shown that 2 at.\% and 4 at.\% of $\mathrm{Nb}$ admixture resulted in significant rise of coercivity and $(B H)_{\max }$ for annealed samples. This is probably due to more refined microstructure of annealed samples.

\section{Conclusions}

It was shown that the rapidly solidified $\left(\mathrm{Nd}_{10} \mathrm{Fe}_{67} \mathrm{~B}_{23}\right)_{100-x} \mathrm{Nb}_{x}$ (where $x=1,2,4$ ) alloy ribbons have an amorphous structure and soft magnetic properties. The heat treatment of these ribbons at temperatures higher than $963 \mathrm{~K}$ leads to the nucleation and growth of the $\mathrm{Nd}_{2} \mathrm{Fe}_{14} \mathrm{~B}$ hard magnetic phase. XRD and DSC studies showed that during annealing of ribbons of low $\mathrm{Nb}$ content (1 at.\%) the $\mathrm{Nd}_{2} \mathrm{Fe}_{23} \mathrm{~B}_{3}$ metastable phase is formed. However, in samples with higher $\mathrm{Nb}$ content (2 and 4 at.\%) the $\mathrm{Nd}_{1+\varepsilon} \mathrm{Fe}_{4} \mathrm{~B}_{4}$ paramagnetic phase is formed for samples annealed above $963 \mathrm{~K}$. Furthermore, larger doping of alloy with $\mathrm{Nb}$ results in gradual increase of coercivity. Addition of 2 at.\% of $\mathrm{Nb}$ causes significant increase of $(B H)_{\max }$ to a value of about $25 \mathrm{~kJ} / \mathrm{m}^{3}$.

\section{References}

[1] N. Chaban, Y.B. Kuzmin, N.S. Bilonizhko, O.O. Kachmar, Dopovidi N.W.P. Acad. Nauk. Ukr. RSR Ser. A Fiz. Mat. Tekh. Nauk 10, 873 (1977).

[2] M.P. Thompson, Proc. IEEE 97, 1758 (2009).

[3] J.I.R. Betancourt, Rev. Mex. Fis. 48, 283 (2002).

[4] A. Manaf, R.A. Buckley, H.A. Davies, M. Leonowicz, J. Magn. Magn. Mater. 101, 360 (1991).

[5] P. Pawlik, H.A. Davies, W. Kaszuwara, J.J. Wysłocki, J. Magn. Magn. Mater. 290-291, 1243 (2005).

[6] R. Tamura, S. Kobayashi, T. Fukuzaki, M. Isobe, Y. Ueda, J. Phys. Conf. Ser. 144, 012068 (2009).

[7] M. Szwaja, P. Pawlik, J.J. Wysłocki, P. Gębara, Archiv. Mettal. Mater. 57, 233 (2012).

[8] J. Zhang, K.Y. Lim, Y.P. Feng, Y. Li, Scr. Mater. 56, 943 (2007).

[9] H. Mayot, O. Isnard, J.-L. Soubeyroux, J. Magn. Magn. Mater. 316, e477 (2008). 